\title{
De buena madera
}

Una experiencia de trabajo colectivo con jóvenes en situación de calle de la Ciudad de Rosario (2015)

\section{Luciana Gracia}

Licenciada en Trabajo Social (UNR)

Maestranda en Salud Mental (UNER)

Docente Escuela de Trabajo Social (UNR)

Coordinadora del Área de Intervención en

Situaciones de calle, Secretaría Desarrollo

Social, Municipalidad de Rosario

Correo: lugraog@hotmail.com 
Resumen

Este texto tiene como objetivo exponer una experiencia de trabajo que se realiza por operadores de calle del Área de Intervención en Situaciones de Calle, dependiente de la Secretaria de Desarrollo Social de la Municipalidad de Rosario. Lo novedoso de este trabajo es la intervención grupal con jóvenes de entre 18 y 28 años, de ambos sexos, que transcurrían sus días en la calle. La herramienta con la que trabajamos fue el Programa Nueva Oportunidad, que nos da un marco de trabajo a través de una capacitación en el oficio de carpintería. Para la selección de los jóvenes, tomamos algunos criterios establecidos a raíz del conocimiento que de ellos teníamos, que marcaban diferencias con otros jóvenes. El objetivo principal es problematizar con ellos su historia de vida, desestructurar algunas costumbres propias de la vida en calle, generar herramientas que les permitan pensarse como personas con derechos y protagonistas activos de sus vidas, con posibilidades de construir un proyecto de vida diferente al que hasta ahora venía "dado" por las circunstancias.

\section{Palabras claves}

Situación de calle - jóvenes - proyecto de vida
Abstract

This text has as aim expose an experience of work that is realized by operators of street of the Area of Intervention in Situations of Street, salesman of the Secretariat of Social Development of Rosario's Municipality. The new of this work is the intervention grupal with young women of between 18-28 years of both sexes that were passing his days in the street. The tool with which we work was the Program New Opportunity, which gives us a frame of work across a training in the trade of carpentry. For the selection of the young persons we take some criteria established immediately after the knowledge that of them we had, that were marking differences with other young persons. The principal aim is problematizar with the younger his history of life, desestructurar some own customs of the life in street, to generate tools that allow them to be thought as persons by rights and active protagonists of his lives, with possibilities of construír a life proyect different to which till now it was coming "given" by the circumstances.

\section{Keywords}

Street situations - younger

- life proyect 


\section{Propuesta de trabajo}

Allá por mayo de 2015, cuando comenzamos a conocerlos, de forma individual, en el marco del Refugio Municipal ${ }^{1}$, los trabajadores del equipo pensamos que podía realizarse una intervención diferente con ellos. Este Área ${ }^{2}$ trabaja con esta población desde hace muchos años, pero siempre de forma individual. Luego de ciertas evaluaciones de nuestro trabajo llegamos a la conclusión de que, con algunas personas, fundamentalmente jóvenes, es necesario un mayor acompañamiento y alguna referencia más fuerte desde donde construir otras alternativas. Es así como surge la idea de un trabajo grupal. La lógica del Programa Nueva Oportunidad ${ }^{3}$ encuadraba con nuestros objetivos, ya que tiene como eje fundamental el mayor acompañamiento de los sujetos.

Ana P. Quiroga dice que "en cada experiencia hay un aprendizaje explícito que se objetiva y condensa en un contenido o en una habilidad" y que, a su vez, "la experiencia en la que se desarrolla ese aprendizaje deja una huella, se inscribe en nosotros afianzando o inaugurando una modalidad de ser-en-el-mundo, de interpretar lo real, de ser-en-el-mundo para nosotros”. Este aprendizaje estructurante, profundo, es el que buscamos en cada encuentro. Para nosotros no es tan importante el aprendizaje del oficio, como así tampoco sabíamos

1 Refugio Municipal: es una institución dependiente de la Municipalidad de Rosario, un lugar de hospedaje transitorio para hombres mayores de 18 años en situación de calle. Funciona todos los años desde 2011, en temporada invernal, desde las 19 hasta las 8 horas del día posterior. Además de un lugar donde dormir, ofrece un lugar donde asearse, ropa limpia, comida, y posibilidad de trabajo sobre su situación articulando con el Área de Intervención en Situaciones de Calle.

2 Área de Intervención en Situaciones de Calle: es la única Área del Estado que trabaja específicamente con la esta población. Desde 1997 esta Secretaría de la Municipalidad trabaja con la población de calle, las formas de organización del trabajo y de abordar la intervención se ha ido modificando en los diferentes contextos sociales, políticos, económicos que hemos atravesado. Desde 2012 se constituye como Área dependiente de la Dirección General de Infancias y Familias, agrupando en la misma a todos los operadores de calle de la Secretaría y abordando todas las franjas etarias.

3 Programa Nueva Oportunidad: es un programa gestionado por el gobierno de la Provincia de Santa Fe y el Municipio de Rosario, que cuenta con talleres destinados a la inclusión socio-laboral de jóvenes de entre 16 y 30 años que se encuentran en situaciones de vulnerabilidad en distintos barrios de la ciudad. Se propone crear lazos institucionales con los jóvenes y acompañarlos en la construcción de un proyecto de vida y su inserción laboral, a través del accionar coordinado con diferentes equipos territoriales. Dicho programa es pensando utilizando la capacitación en oficio y el acompañamiento cercano de trabajadores del estado y/u organizaciones de la sociedad civil para lograr efectos del que impliquen ciertos cambios en la vida de los pibes. 
si iba a ser realmente una posibilidad de salida laboral, lo destacable es todo lo derivado de ese proceso, las inquietudes, las reglas institucionales, los horarios, las asistencias/inasistencias, los compromisos asumidos, las discusiones/peleas entre ellos, las ansiedades, las convivencias en los hospedajes donde viven, cada cuestión que hace a la vida cotidiana.

Los objetivos específicos se fueron planteando en el andar de la experiencia, ya que poder trabajar con ellos estas cuestiones, de forma grupal e individual depende de lo que amerite, es fundamental para pensar en generar mayor autonomía. Generalmente los entornos institucionales y familiares, en la infancia/adolescencia, tienen como función lograr esos aprendizajes que les permitirán hacer elecciones evaluando prioridades, tomar decisiones evaluando las consecuencias, pensarse parte de un grupo de pares con quienes se puede resolver problemas de forma conjunta.

Siguiendo con el pensamiento de Pichon-Rivière y Quiroga, cuando definen la matriz o modelo interno de aprendizaje, como "la modalidad con la que cada sujeto organiza y significa el universo de su experiencia, su universo de conocimiento" nuestras acciones apuntan a modificar esa matriz, para que la lente con la cual realizan la lectura del mundo, y de ellos mismos, ya no sea la matriz que solamente se nutre de lo vivido hasta este momento de sus vidas, sino que puedan incorporar algunas otras vivencias en donde sean protagonistas como ciudadanos, como sujetos de derechos. Esta matriz es compleja, tiene una infraestructura biológica, es socialmente determinada e incluye aspectos emocionales, afectivos y esquemas de acción.

Nuestras intervenciones en principio con toda la población, y siempre teniendo en cuenta la singularidad de cada sujeto, tienen como ejes: generar vínculos; reconstruir historias familiares e institucionales; re vincularlos institucionalmente.

La reconstrucción de sus historias familiares e institucionales nos permiten a nosotros poder historizar y comprender los trayectos de vida de los sujetos, y con ellos trabajar la identidad. Algunos de los jóvenes $-\mathrm{O}$ a veces adultos-, ni siquiera han sido inscriptos cuando nacieron, nunca tuvieron DNI, no existen para el Estado, no pueden 
decir su fecha de nacimiento de forma certera y eso trae aparejado algunos inconvenientes no sólo burocráticos sino también de orden subjetivo.

La re-vinculación institucional o el fortalecimiento de vínculos ya establecidos, es importante porque implica que los sujetos estén insertos en una red estatal o de la sociedad civil que cumplen diferentes funciones. Centro de Salud, escuela, club, son algunas de las instituciones que les permiten establecer redes, crear otros vínculos, cuidarse, reconocerse.

Muchos de ellos llevan mucho tiempo relegados de las redes de lazos sociales primarios, Castel habla de la sociabilidad primaria, entendiendo por ella a "los sistemas de reglas que vinculan directamente a los miembros de un grupo, sobre la base de su pertenencia familiar, de vecindario, de trabajo, y tejen redes de interdependencias sin la mediación de instituciones específicas" (Castel, 1997). Con muchos de estos sujetos esta red no existe, se dañó hace tiempo atrás, ya fueron agotados estos lazos que los unían a un grupo. Nos encontramos con que estas personas no tienen más redes que las que armaron en la calle. En general, en su niñez y adolescencia no contaron con el cuidado, la autoridad, con el vínculo afectivo de adultos. No es menor la vinculación entre desintegración familiar y sus consecuencias a la hora de construir un proyecto de vida.

\section{¿Con quiénes?}

Para Pichon-Rivière, "el hombre se configura en una praxis, en una actividad transformadora, en una relación dialéctica, mutuamente modificante con el mundo. Relación destinada a satisfacer sus necesidades. El carácter fundante de esta relación de transformación reciproca define al sujeto de la praxis como sujeto esencialmente cognoscente y sitúa en primer plano el análisis de los procesos de aprendizaje". Ser partícipes y protagonistas de las actividades en ese grupo, permitieron a estos jóvenes transformarse y transformar el alrededor. Discutimos quiénes, para qué, por qué ahora, cómo ha- 
cerlo y fundamentalmente qué hacer, o sea, construimos criterios y objetivos claros.

De todas las personas que asistían al Refugio Municipal, como equipo de trabajo coincidíamos que había un grupo de jóvenes de entre 18 y 28 años, que tenían características similares: con trayectoria en situación de calle de niño o adolescentes; sin vínculos familiares o vínculos débiles; que nunca habían trabajado en un empleo formal; que si bien la vida que hasta este momento conocían hacía muy difícil aceptar límites y reglas de convivencia, eran permeables a respetarlas en las instituciones por las que transitaban mayormente; con inquietudes e iniciativas; con cierto atravesamiento del consumo de sustancias, pero que no llega a ser problemático o abusivo; sin referencias geográficas a las que vincularse. Podríamos relevar algunas dificultades subjetivas que hacen síntoma en diversos aspectos, como poca tolerancia a la frustración, dispersión, dificultades para comprender consignas, poca paciencia para esperar resultados, entre algunos de ellos. Y todos compartían tiempo diurno en el Centro de la Juventud ${ }^{4}$. Se le sumaba una joven con las mismas características pero que ya estaba viviendo en una pensión ${ }^{5}$ de forma intermitente.

Lo más importante que rescatamos es que todos no sólo enunciaban querer "hacer algo diferente de sus vidas", sino que con ciertas acciones lo iban sosteniendo, por ejemplo, asistir a la escuela, asistir a las entrevistas con el equipo, solicitar acompañamiento al Centro de Salud, entre otras acciones que pueden parecer pequeñas o cotidianas pero que, para nosotros, evaluando su trayectoria de vida eran muy importantes.

Esos eran algunos rasgos que nos permitieron pensar en la posibilidad de trabajar en grupo. Y para ello surge la idea de pensar en la inserción en el Programa Nueva Oportunidad. El programa nos

4 Centro de la Juventud: dependiente de la Dirección de Políticas de Juventudes de la Secretaría de Desarrollo Social de la Municipalidad de Rosario, a orillas del Río Paraná encuentra un galpón del viejo puerto de Rosario que fue reciclado y acondicionado. En él funciona desde 1998 el Centro de la Juventud, un espacio óptimo para el desarrollo de actividades que tiene a los jóvenes como principales protagonistas.

5 Se llama pensión a las habitaciones que se arrendan en casas particulares, los montos son más bajos que los de alquilar una casa, y si requisitos tales como garantías. 
provee de un espacio de capacitación en una organización social, el pago de un incentivo para los jóvenes y el formato de dos días de capacitación y un día de trabajo libre que queda a decisión de quienes acompañamos para re trabajar lo que creamos conveniente con los jóvenes.

Por el mes de agosto realizamos encuentros con la excusa de desayunar o almorzar para comentarles nuestra propuesta e ir generando el grupo de trabajo. Fue una óptima experiencia ya que esos primeros encuentros, aunque desordenados o desbordantes - por las emociones que causaban-, fueron fundamentales para que pudieran visualizar una propuesta diferente a las que hasta ahora conocían ${ }^{6}$. En octubre comenzamos a asistir a la capacitación.

\section{Trayectorias de vida}

Bourdieu piensa la trayectoria como "serie de las posiciones sucesivamente ocupadas por un mismo agente (o un mismo grupo) en un espacio en sí mismo en movimiento y sometido a incesantes transformaciones" . Desde este concepto es desde donde parten un grupo de trabajadoras sociales de la UNER para decir que "intentar reconstruir las trayectorias de los sujetos a través de sus historias de vida, supone una mirada integral de las posiciones objetivas transitadas y ocupadas por los actores, teniendo en cuenta la estructura y volumen de los diferentes capitales disponibles, no como enumeración de acontecimientos sino como una suerte de dibujo que enlaza las sucesivas posiciones" . Para nosotros es importante reconstruir esa trayectoria para poder pensar junto al otro cómo seguimos, cuál es el fundamento de nuestra intervención. Además, permite al sujeto de nuestra acción, atar partes de su historia que estaban sueltas, inconexas, o muchas veces pensar y problematizar lo ocurrido. Es por ello que,

6 Aclaramos que, en general, desde hace muchos años hay ofertas de capacitaciones en oficios en el ámbito municipal, que esta población, por un lado, comienza y no puede sostener, por las reglas que eso implica - horarios, sistematicidad, higiene, etc.- y en otros casos se sostienen, y al no conseguir luego inserción laboral, se comienza a acumular diferentes cursos con el solo hecho de ser parte de esa red o cobrar alguna beca. 
brevemente y sin ahondar demasiado en sus historias de vida, pero sí precisando algunas características, damos cuenta de quiénes son estos jóvenes con los que trabajamos.

Pablo tiene 18 años. Es flaco, alto y de pocas palabras. Asistió al Refugio Municipal desde mayo, lo conocemos ya que uno de los compañeros que allí trabajaba estaba preocupado por el DNI del joven. Hicimos búsquedas de todas las formas posibles y con todos los recursos institucionales a nuestro alcance para rescatar su número de DNI y poder realizar un ejemplar nuevo, pero todo fue en vano. Con Pablo, tratamos de encontrar alguna información que nos sirva para poder buscar datos de sus padres o algún familiar que nos ayude. Llegamos a la casa del padre. Y allí pudimos detectar que mucho de su relato era fantasía, que algunos datos no eran reales, que había mucho de su deseo, pero no tanto de lo que pasaba en realidad. Por ejemplo, su padre biológico nos manifiesta en una entrevista que "no le interesaba" la vida del joven, no había tenido una buena relación con su madre y no era de su interés tener vínculo alguno con Pablo, por otro lado, su abuelo paterno no tenía muchos registros de su nieto, lo llamaba el "chico ese" recordaba haberlo visto hacía varios meses atrás, pero ni siquiera podía decirnos donde estaba hoy. Y su madre había fallecido en Córdoba dejando dos niñas al cuidado de algún familiar. Encontramos algunos hermanos que el joven no sabía de su existencia, y por lo que estos pudieron informarnos respecto del nacimiento de Pablo y su identidad, llegamos a la conclusión de que nunca había sido inscripto. Es así como comenzamos junto a él el trámite de inscripción tardía. Defensoría, Registro Civil, Hospital, Comisaria y ahí inició Pablo la historia para lograr tener su DNI, en el Registro Nacional de Personas. A su vez, ingresó a un aula radial, y por primera vez pudo firmar algo con su nombre. Pablo vivió gran parte de su vida en calle, en ocasiones junto a algún hermano, en la mayoría de los casos solo, la situación en la que vive su padre y vivía su madre eran de pobreza extrema. De forma intermitente asistió a la escuela, pero no sabe leer ni escribir. Como en muchos casos de niños en situación de calle, siempre buscaba el reconocimiento y afecto de sus padres, pero no lo podía lograr. La forma más rápida de resolver 
los conflictos es a los golpes, suele tener algunos momentos de melancolía, y recurre a las sustancias para paliar la tristeza. Su léxico es muy precario, se le dificulta mucho fundamentar sus acciones, o resolver situaciones de otra forma que no sea con violencia, lleva sobre su cuerpo marcas de lesiones provocadas por él mismo.

Marcelo tiene 22 años. En el Registro Social ${ }^{7}$ que existe en la Secretaria de Desarrollo Social, las intervenciones familiares con él se llevan varias hojas, y siempre se describen las mismas problemáticas: situación de calle, situaciones de violencia familiar, desnutrición de sus hermanos. Marcelo sufre convulsiones, asiste a la escuela, por sus propios medios gestionó el Pro.Gre.Sar ${ }^{8}$, es ordenado, prolijo en su higiene, su ropa está siempre combinada. En su núcleo familiar encontramos a su madre que - por lo que hemos podido reconstruir con otros profesionales que conocían la situación de Marcelo cuando niño- siempre ha estado ausente. Sus hermanos algunos están detenidos y otros, según él mismo "andan en cualquiera". Tiene momentos "de colgarse", o de desaparecer de las actividades, pero está siempre atento a las charlas y es muy cuidadoso de lo suyo. Marcelo muestra dificultades a la hora de escuchar fundamentos o explicaciones, se comporta como un niño, caprichoso, no escucha argumentos, se enoja fácilmente, no tiene paciencia para lograr determinados objetivos.

A Jeremías lo conocemos desde hace más tiempo, la última vez que lo vimos el año pasado había logrado vivir en una pensión y estaba trabajando en un cyber. Lo dejamos de ver porque asistía el Centro de Salud, a un espacio terapéutico, y estaba muy a gusto con lo que estaba haciendo. A meses de abrir el Refugio, Jeremías ingresó, ya que estaba en situación de calle. Tiene 28 años, fue adoptado junto a su hermano cuando eran niños. La vida de los dos se complica

7 Registro Social: es una herramienta informática que se vale la Secretaría de Desarrollo Social, donde los diferentes equipos cargan las intervenciones con los sujetos con los que se trabaja. Permite recuperar la historia institucional de las personas.

8 Pro.Gre.Sar.: el programa otorga una suma fija de dinero mensual y pueden acceder todos los jóvenes argentinos de entre 18 y 24 años inclusive que acrediten estar inscriptos o asistan a Instituciones educativas habilitadas, siempre que, al momento de la solicitud sean desocupados o trabajadores formales en relación de dependencia, entre otras características que deben cumplir. 
cuando sus padres fallecen en el término de algunos meses. En ese momento las deudas que quedan, la poca edad de los adolescentes, y la falta de posibilidades de hacerle frente a esos problemas, termina haciendo que se remate la propiedad. Sus tíos dijeron ayudarlos, compraron la casa en el remate, pero hicieron uso de la misma sin incluir a los hermanos. Jeremías y Mauricio tomaron caminos diferentes, y quizás por tener diferentes herramientas para afrontar la vida cotidiana el más perjudicado fue Jeremías. Llega al Área en el año 2014 porque un vecino que lo ayudaba sintió que ya no podía hacer mucho más y solicita ayuda en el Centro de Salud Martin ${ }^{9}$. Por el trabajo que realizamos entre las dos instituciones en lo cotidiano, la trabajadora social del efector solicita que abordemos la situación juntos. En un primer momento con él, volvimos a trabajar la continuidad del espacio terapéutico, el cuidado de su salud, la búsqueda nuevamente de una pensión. Encontramos ciertos límites porque su aspecto personal había desmejorado, lo que el espacio terapéutico había logrado se vuelve a derrumbar, haciendo que su actitud sea más rígida respecto a que él siempre sabe todo, que no necesita aprender nada de nadie. Cuando se cierra en ese lugar es difícil para nosotros encontrar algún hueco por donde entrar a su mundo, y genera en el resto de las personas que lo rodean rechazo, quedándose solo.

Gabriel tiene 29 años, en principio lo conocimos en Centro de la Juventud ya que pasaba todos sus días allí, es de contextura grande, y le gustaba jugar al ajedrez. Así fue como nos pudimos acercar a él. Reacio al contacto, varias veces alcoholizado lo hemos encontrado. Con una voz importante, que muchas veces intimidaba a los que andaban por ahí. Es una persona intensa, que mira con desconfianza. Cuida coche cerca de la costanera. Su familia vive en otra localidad y en varias oportunidades él aparecía por Rosario en la Costa Central pasando su tiempo y pernoctando por ahí. El horizonte de la intervención parecía ser complejo ya que no nos habilitaba a nada. En el Refugio, se presentaron inconvenientes por su incapacidad de aceptar normas, o su estado de embriaguez. Su padre lo traía a cuidar coches 
a las calles del centro rosarino desde pequeño, este señor solía quedar detenido por robos. Según él mismo lo manifiesta, en la escuela no la pasaba bien, porque se burlaban de él, a pesar de ese obstáculo logró terminar $7 \mathrm{mo}$ grado. También, al igual que Pablo, para él todo se resolvía con violencia, incluso generando inconvenientes en el Centro de la Juventud con el personal, con hombres y mujeres. Gabriel fue de los que más nos sorprendieron en este proceso, él fue encontrando la forma de moderar su intensidad, logró hacer vínculos en la pensión en la que vive, admitió su problema con el alcohol, la necesidad de tener un trabajo un poco más estable, desde hace unos meses asiste a un espacio terapéutico a su pedido.

Leandro apareció supuestamente expulsado de su casa familiar, luego de que su madre conformó una nueva pareja, vende la vivienda y se va a otro lugar. Según sus relatos, él y sus hermanos quedaron sin lugar donde vivir. Leandro tiene una hija, con una ex pareja con quien tiene una relación compleja. Es hermético, pero las pocas palabras le alcanzan para pedir "algo de ayuda". Luego fuimos armando su historia, y nos encontramos con que el hermano más chico había sido acribillado a tiros desde una moto cerca de su barrio, y otro que a raíz de un hecho similar recibió un tiro en la médula que le valió parálisis de sus miembros inferiores. Su madre, según relatan profesionales de instituciones del barrio, nunca pudo hacerse cargo de la crianza y contención de sus hijos, es una familia pobre sin presencia paterna, ya que el progenitor falleció cuando Leandro era un niño. Fue el primero que solicitó un espacio con un psicólogo, asiste a un psicólogo de la red del Servicio Comunitario del Colegio de Psicólogos de la Ciudad de Rosario.

Sebastián tiene 28 años, desde los 16 su vida alternó la calle y las instituciones (hogares-cárcel-refugio-hospitales). Su madre biológica los habría abandonado en el rancho donde vivían, a Sebastián y sus tres hermanas más pequeñas, cuando este tenía 10 años. Y fueron derivados a la casa de una familia en un pueblo cercano a Rosario. A los 16 años, según sus relatos, no soporta más la relación violenta con quien cumple la función de padre y comienza a transitar la calle en el centro rosarino. Alterna hogares, calle, pero no regresa 
a su casa. Cuando llega a los 21 años, por acumulación de causas y ante un hecho de robo, lo condenan a 6 años de prisión, cumple 4 y el último tiempo lo transita en libertad condicional; lo derivan al Refugio ya que no contaba con casa familiar donde poder vivir, ni acompañarlo. Tenemos con él variadas intervenciones, conjuntamente con Centro de Salud Martin, Hospital Agudo Ávila, Juventud, entre otros. Cuando dejamos de intervenir con él, estaba viviendo en una pensión. En todo este tiempo sin trabajar con Sebastián, este volvió a estar en situación de calle, y su salud está tan deteriorada que pasó dos meses internado en el hospital con múltiples diagnósticos, egresó con un promedio de 10 tipos diferentes de pastillas diarias. Está viviendo en un hogar convivencial comunitario dependiente de una fundación, con otras personas que lo doblan en edad. La convivencia es buena, Sebastián es una persona capaz de generar empatía en poco tiempo, y por otro lado compadecimiento porque es en apariencia un joven frágil. Lo que no puede evitar es la plaza, la misma plaza en donde corren todo tipo de sustancias, y que lo llevan a pasar en vela las noches, sin tomar su medicación, comiendo de forma intermitente. Las intervenciones nuevamente con Sebastián se disparan por el lado de la salud/salud mental. Padece esquizofrenia, HIV, y patologías derivadas de éste. Cuenta con pensión por discapacidad y certificado. Su interés nunca fue la capacitación en sí misma, sino la beca, y todo lo que pueda obtener derivado de ese espacio - paseos, almuerzo, desayuno, etc.

María tiene 22 años, un hijo que está en proceso de adopción, y está embarazada. Su vida desde niña la transitó en hogares y en la calle. Proveniente de una familia muy pobre, con una madre que no ha podido ocuparse de la crianza de sus hijos ya que de los 12 hermanos algunas mujeres también transitan la calle y han sido alojadas en hogares, otros nadie sabe dónde están, el que se supone que es su padre -ningún hermano lleva el apellido de quien se cree es su padre- está detenido desde hace alrededor de 10 años por una causa de abuso hacia ella y una de sus hermanas. Durante muchos años su consumo de sustancias ha sido muy problemático, con acciones que la lastimaban físicamente, apegándose a relaciones amorosas violentas, 
en situaciones de prostitución que por su consumo abusivo de sustancias eran altamente peligrosas para su salud. Está muy referenciada a un Centro de Día, y con algunos trabajadores de dicho lugar. Cuando comenzamos a trabajar con ella estaba en situación de calle, atravesada por el consumo. Luego de un trabajo conjunto con el Centro de Salud Martin y la acompañante terapéutica, hemos logrado que María pueda problematizar su situación, aceptar vivir en una pensión - no sin inconvenientes, luego de rotar por varias por cuestiones de convivencia - y sostenerlo, administrarse, realizar actividades y fundamentalmente que el consumo de sustancia no sea problemático ni abusivo, apuntando a la reducción de daños. Su deseo de ser madre y su actitud enamoradiza la llevó a constituir una pareja, y volver a embarazarse, sin poder planificar otro proyecto, que le diera mayor autonomía.

Fabián tiene 18 años, siempre pensamos que podía ser alguien del grupo, pero él nunca pensó lo mismo. Lo conocimos por derivación de la Secretaría de Inclusión Municipal. Con imposibilidades de comprometerse o de mantener los encuentros, y con algún problema del orden de la salud mental, que con el acompañamiento de la Secretaría de Inclusión develamos como un retraso madurativo leve. Al Refugio asistió en varias oportunidades, pero sus comportamientos aniñados en un contexto de alrededor de 30 hombres en su mayoría mayores de 30 años, traía serios inconvenientes, sumado a la imposibilidad de mantener ciertos códigos para con los compañeros, lo terminaban expulsando y muchas veces para resguardarlo a él mismo. El resto de los jóvenes tampoco lo aceptaba como parte del grupo, en variadas ocasiones lo acusan de robos. Es de andar solitario.

\section{Las intervenciones grupales, siempre desde la singularidad}

Como dijimos anteriormente, comenzamos con reuniones distendidas para instalar algunos interrogantes. Por ejemplo, qué querían hacer ellos a futuro, cómo se veían, dónde iban a vivir, qué rescataban 
de la convivencia en el Refugio, entre otras preguntas que surgían al andar. Allí, de a poco fuimos despejando la idea de que nadie quería volver a dormir en la calle, pero también ninguno de ellos tenía donde volver, es por ello que surge la posibilidad de pensar en una pensión, con todo lo que ello implicaba. Algunos, los que menos tiempo estuvieron en calle, pudieron resolverlo solos y más rápido, solamente necesitaron el apoyo económico. Otros no sabían por dónde comenzar porque nunca habían tenido la posibilidad de hacerlo, con ellos comenzamos desde tomar un diario y buscar hasta acompañarlos a los lugares, mediar con los encargados cuando se presentaba algún inconveniente de convivencia, acompañar a cobrar los subsidios, etc. Así fue como a una semana del cierre del Refugio todos tenían ya pago su mes de pensión.

Se presentaban situaciones difíciles de comprender, porque no querían sentirse solos, y dos de ellos teniendo lugar donde vivir volvieron un par de noches al refugio. El argumento era que allí los esperaba alguien para charlar, la comida hecha, la cama armada. Lo tuvimos que charlar y problematizar con ellos. Cuando todos comenzaron a vivir en las pensiones aparecieron otros problemas, simples, que nunca hubiésemos pensado, la soledad. El comer, cocinar, dormir solos, en un lugar desconocido. Se dieron algunas crisis, alguno que se fue a dormir a la esquina junto a otros compañeros de la calle, otro que recayó en una crisis de consumo, planteos de atención en las oficinas del Área, no faltó el que se solidarizó con algún "compañero de ranchada" y lo llevó a dormir a la pensión cuando eso no está permitido. Siempre todo mediado por muchas charlas, grupales, individuales. Cada una de estas situaciones implicaron e implican trabajarlo grupalmente, y en entrevistas individuales, abriendo la posibilidad de escucharnos, de restarle dramatismo a alguna situación, dándole lugar a la angustia, pero a la reflexión también, buscando soluciones. No son cuestiones fuera de lo que cualquier ser humano vive en momentos de su vida, en general las familias y las instituciones por las que transitamos en nuestra infancia/adolescencia nos nutren de herramientas para poder afrontar las vicisitudes de la vida. Pero cuando eso no funciona de esa manera en esa etapa, transcurrido el 
tiempo, cuando suceden algunas de estas cosas los sujetos - en este caso jóvenes- no tienen a quién ni adónde apelar.

Comenzamos el curso de capacitación, no sin dificultades, inasistencias, berrinches, peleas entre compañeros, intentos de llamar la atención, todo aquello que puede ocurrir en un grupo de jóvenes, con características de adolescentes. Las situaciones de violencia se solían dar, o eran relatos de lo vivido el fin de semana. Todos, de lo que hemos podido reconstruir, vienen de núcleos familiares atravesados por la violencia, pensando en la violencia en los términos en los que explica Tonón. Ella define a las "violencias intrafamiliares como los actos y carencias, producidas por los padres o las personas encargadas del cuidado, que dañan gravemente a los niños/as atentando contra su integridad corporal, desarrollo físico, afectivo, intelectual y moral y cuyas manifestaciones son el descuidado y/o lesiones de orden físico y/o psíquico y/o sexual. Incluyo acciones y/u omisiones" . La indiferencia de la madre de Pablo manifiesta en su no inscripción, la negación del padre, y la distancia de sus hermanos lo llevan todo el tiempo a fantasear con familias que no existen, a poner de manifiesto la soledad, y canalizarlo en la violencia para con su propio cuerpo y para con los otros. A Jeremías los tíos no sólo no lo cuidaron, sino que lo expulsan del entorno, el hermano lleva su vida sin incluirlo. En muchos casos, la falta de cuidados parentales de estos jóvenes en momentos de su niñez y adolescencia hoy se plasman en conductas que reproducen la violencia con el otro y consigo mismo - lesiones físicas, consumo abusivo de sustancias, violencia de género, etc. María se crió en la calle y en hogares, al igual que sus hermanos. Algunos de ellos nadie puede dar cuenta en dónde están.

Shaw (2002), retomando estudios de México y Colombia sobre los niños en situación de calle, utiliza una idea para explicar algunas cuestiones que tiene que ver con dinámicas familiares alejadas de acciones enmarcadas en el cariño, en la demostración de cariño, de amor hacia los niños. Lo que explicaría que éstos — ante algún problema- definan resolverlo fuera del núcleo familiar, ya que considerarían que sus papás no los quieren, o que busquen ese afecto y contención fuera del hogar, en grupos de pares, en vecinos, comerciantes. 
También Ariza y De Olivera toman la dimensión afectividad para hacer referencia a un ámbito cualitativo de la familia y vinculada a las emociones y la subjetividad. "Pertenece al campo de la acción social afectiva. Sentir, pensar y actuar son procesos íntimamente relacionados y la acción emocional suele desencadenar una acción vinculada a ella" .

Todos los viernes desarrollábamos una actividad desde el ocio y lo educativo, charlas con profesionales de PROMUSIDA, del Área de Diversidad Sexual, Instituto de la Mujer, Secretaría de Derechos Humanos de la Provincia, paseos al Museo de la Ciudad a la muestra de Radio, a la Granja de la Infancia ${ }^{10}$, Almuerzo en el Camping de ATE ${ }^{11}$, en el Polideportivo Saladillo, cocinamos en un Centro de Convivencia Barrial ${ }^{12}$, realizamos reuniones de trabajo con los jóvenes y el equipo de operadores de calle para tratar algunos problemas que iban surgiendo dentro del grupo —administración de dinero, búsqueda laboral, problematización de las acciones violentas, respeto por la diversidad de género, conceptos de familias, etc.

Así, fuimos llegando a diciembre, con un grupo más en sintonía, con un objetivo a corto plazo que es la producción de juegos de ingenio para la venta en la Feria de Navidad ${ }^{13}$, con un nombre propio

10 Según lo que expresa la página oficial de la Municipalidad de Rosario, la Granja de la Infancia es un espacio en el cual es posible relacionarse con la naturaleza, sintiéndose parte de ella y responsable de sus cambios. Posibilita infinidad de recorridos, de juegos, de sueños, de visiones del mundo, es el lugar para aprender a respetar tanto las diversas formas de vida como las diferentes ideas y espera que cada ciudadano sepa disfrutarla y vivenciarla con libertad y responsabilidad. Su propuesta promueve la interacción entre naturaleza y cultura y propicia que sus partícipes asuman un rol protagónico en el desarrollo de la misma desde una perspectiva ecológica y social. Presenta múltiples espacios de participación integrados entre sí que intentan ser un sistema productivo y sustentable. En estos espacios los visitantes intervienen mediante diferentes actividades como sembrar, regar, desmalezar y alimentar a los animales.

11 Asociación Trabajadores del Estado es un sindicato de trabajadores del Estado nacional, provincial y municipal.

12 Los Centros de Convivencia Barrial (CCB) son instituciones pertenecientes a la Secretaría de Desarrollo Social de la Municipalidad de Rosario. Promueven actividades para niños, jóvenes y adultos mayores. Están ubicados estratégicamente en los barrios de mayor vulnerabilidad de la ciudad y allí se desarrollan instancias de capacitación, recreación, consultoría legal y de salud, entre otras. Posibilitan la inclusión de grupos familiares completos propiciando el pleno ejercicio de sus derechos.

13 Feria de Navidad: todos los años la Secretaría de Cultura y Educación municipal, organiza una feria en la Plaza Pringles de la ciudad de Rosario durante los días previos a las fiestas, donde los artesanos que habitualmente exponen en las ferias de fines de semana venden sus productos, así como también algunos emprendimientos realizados por Programas o Equipos de diferentes Secretarías de la Municipalidad. 
para los productos: “De Buena Madera”. La feria la sostuvieron ellos con apoyo de los profesionales del Área, se desenvolvieron en la venta de los productos solos, y definieron qué hacer con las ganancias.

Llegado el mes de febrero, fue una inquietud de varios de ellos comenzar la escuela para terminar en algunos casos la primaria y en otros el secundario.

\section{Adónde estamos}

Silvia Bleichmar consideraba que la función principal de la escuela es producir subjetividad, "tiene que ayudar a producir subjetividades que no solamente sirvan para la aplicación del conocimiento, sino para la creación de conocimientos y de conocimientos con sentido, no solamente con el único sentido de ganarse la vida, sino con sentido". Nuestras acciones están guiadas por esa lógica, no somos escuela, pero estos jóvenes adultos hoy necesitan cierto encuadre institucional que les permita construir un proyecto de vida. Y a decir de Bleichmar esa sería la gran tarea educativa, "restituir la idea de que al futuro lo tenemos que construir". Recordemos que estos jóvenes, en su niñez y adolescencia carecieron de adultos o instituciones que pudieran establecer ciertos encuadres o legalidades. Y hoy eso trae aparejado en la adultez ciertas dificultades, por ejemplo, la entrada a circuitos de economía formal, o simplemente las tareas de la vida cotidiana ${ }^{14}$ que muchas veces se les revelan como expulsivas o inalcanzables.

Dice Castoriadis que "los individuos devienen lo que son absorbiendo e interiorizando las instituciones; en cierto sentido, ellos son la encarnación principal de esas instituciones. Sabemos que esta interiorización no es en modo alguno superficial: los modos de pensamiento y acción, las normas y los valores, y, finalmente, la identidad misma del individuo depende de ella” . Es por ello que hoy, para este equipo,

14 Como saber cocinarse, manejar dinero, hacer compras, convivir con otros, lavar ropa, tomar decisiones, establecer prioridades, etc. Por ejemplo, lavar la ropa no es sólo un problema que se les presente a ellos, en general quienes viven en situación de calle están acostumbrados a usar y tirar la ropa, no está dentro de la rutina lavarla ni dentro de las posibilidades en la calle, lógicamente. Y aun viviendo en una casa se sigue con esas formas. 
esa función casi le es asignada naturalmente por los jóvenes. Buscan constantemente ese límite, la palabra, y muchas veces el reconocimiento y el afecto. Además de los tres días de encuentro ya pautados, varias veces aparecen por las oficinas del Área buscando a alguno/a delos/as operadores/as por algún problema, o simplemente para "hablar". "Los procesos y relaciones mediante los cuales las instituciones para la infancia producen niños se relaciona con la transmisión de la herencia cultural. Esta transmisión tiene tanto una potencialidad reproductora del orden social (y sus relaciones de dominación y hegemonía) como una potencialidad creadora, transformadora de tales relaciones. En estas funciones, las instituciones constituyen un espacio que es social pero también es singular: funcionan como los puentes mediante los cuales las sociedades producen los individuos singulares que las mantendrán vivas como tales. O no....” .

Las personas con las que trabajamos no tienen vínculos afectivos cercanos, los vínculos primarios son escasos o nulos, generalmente no encontramos personas que puedan funcionar como sostén. Están rodeados de pares, de personas en las mismas circunstancias que ellos. En estas situaciones, la mera presencia de otro que se preocupa, que se ocupa, que les da lugar a la palabra, que te propone algo diferente a lo que está acostumbrado, que puede acompañarte al odontólogo para que no tengas miedo, o que te acompaña al médico, o que te lee una hoja que te dan en el hospital cuando no sabes leer, o simplemente te acompaña a buscar un lugar donde vivir, vamos construyendo una subjetividad diferente, vamos modificando ese modelo de aprendizaje interno del que habla Pichon-Rivière, ese que permite pensar un proyecto de vida.

En este momento del proyecto, los jóvenes siguen produciendo juegos de ingenio para poder presentarlo en un puesto en la feria. Todos están viviendo en pensiones.

Leandro y Gabriel solicitaron asistir a terapia, de forma intermitente asisten a consultas de un psicólogo particular, no de la red estatal. Los dos están cursando el primer año de secundaria. Viven en pensiones, Gabriel tiene muchos deseos de conseguir un trabajo es- 
table, hasta ahora genera sus ingresos cuidando coches, $\mathrm{y}$ ha podido decir que su relación con el alcohol es conflictiva.

María ya fue mamá y coopera con el taller desde su casa, allí pinta los juegos que luego son armados por los jóvenes. Hoy esta entrampada en una relación, nuevamente, violenta con su pareja, pero con conciencia que debe salir de ella y con mucho registro del cuidado de esta segunda hija. María está viviendo una etapa nueva en su vida.

Pablo tras unos meses de alejamiento, luego de fracasar una internación por consumo reapareció queriendo continuar con las actividades.

El espacio está vigente aun y se transformó para los trabajadores en una herramienta que puede significar cambios en los sujetos.

Dice Karsz que la potencia de la ideología reside en comprender, que uno puede vivir de determinada forma sabiendo lo que le pasa y por qué ocurre, o sin saberlo, pero que no es lo mismo. Las ideologías "se encarnan en los gestos, en aquello en lo que se lucha. El Trabajo Social no ha sido inventado para solucionar los problemas materiales de la gente, mejor dicho: para solucionar de manera exhaustiva la dimensión material de los problemas de la gente. No puede remplazar ni la acción política, ni el trabajo psicológico, ni las transformaciones sociales...”.

Las condiciones materiales en las que nacieron, vivieron y viven estos jóvenes no son las más favorables para el desarrollo de un sujeto, pero no son los únicos y no todas las personas pobres llegan a vivir en situación de calle. Por eso decimos que es un conjunto de dimensiones que se conjugan para llegar a esta situación. Los programas como los nuestros sólo llegan para trabajar el emergente. No pretendemos modificar esas condiciones porque no está en nuestras manos lograrlo, pero todas las acciones que desarrollamos tienen como finalidad poder generar en el otro ciertas herramientas que les permitan reconocer donde están y por qué, y les posibiliten luchar para modificarlas. 


\section{Referencias bibliográficas}

BLEICHMAR, S. No me hubiera gustado morir en los 90. Buenos Aires, Taurus, 2006.

BOURDIEU, P. "La ilusión biográfica", en: BOURDIEU, P. Razones Prácticas. Paris, Anagrama, 1997. Pp. 74-83.

CASTEL, R. Las metamorfosis de la cuestión social. Una crónica del salariado. Buenos Aires, Paidós, 1997.

CASTORIADIS, C. El mundo fragmentado. La Plata, Terramar Ediciones, 2008.

DE OLIVEIRA, O. Y ARIZA, M. "Desigualdades sociales y relaciones intrafamiliares en el México del Siglo XXI", en: Revista Latinoamericana de Población, vol. 3, N 6, Buenos Aires, enero-junio 2010. Pp. 71-102.

KARSZ, S. "Pero ¿Qué es el trabajo social?". Publicaciones Post Jornadas La investigación en Trabajo Social, Vol. 5, Facultad de Trabajo Social, UNER, Paraná, 2006. Pp. 9-28. [En línea: 18/03/ 2016] Disponible en: http://www.catedras.fsoc.uba.ar/ heler/17.03.08karsz.htm.

LERA, C. Y GENOLET, A. "Trayectorias: un concepto que posibilita pensar y trazar otros caminos en las intervenciones profesionales del Trabajo Social", en: Revista Cátedra Paralela $\mathrm{N}^{\circ}$ 4. Rosario, UNR editora, 2007. Pp. 33-39.

LLOBET, V. ¿̇ábrica de niños? Las instituciones en la era de los derechos de la infancia. Buenos Aires, Noveduc, 2010.

PAMPLIEGA DE QUIROGA, A. "El sujeto en el proceso de conocimiento (Modelos interno o matrices de aprendizaje)", en: Pampliega de Quiroga, A. Enfoques y perspectivas en Psicología Social. Buenos Aires, Cinco,1987. Pp 47-57.

SHAW, K. " Hacia una teoría general de la calle", en: Ministerio Salud. Gobierno de Colombia. 2002 [en línea: 05 de diciembre de 2015] Disponible en: www.minsalud.gov. co/salud/Documents/observatorio_vih/documentos/literatura_interes/Hacia\%20una\%20 teoria $\% 20$ general $\% 20$ sobre $\% 20$ ni $\%$ C3\%B1os\%20de\%20la\%20calle.pdf.

TONÓN, G. Maltrato infantil intrafamiliar. Buenos Aires, Espacio, 2001.

Recepción: 15/04/2016

Aceptación: 15/09/2016 